\section{Individual variation in affective responses to taste stimuli}

\author{
ROSE MARIE PANGBORN \\ University of California, Davis, Calif. 95616
}

Initial experiments on hedonic responses to the taste of sodium-chloride solutions showed that three Ss distinctly liked and five Ss distinctly disliked increasing concentrations. A paired-preference presentation of the same concentrations of sodium chloride resulted in almost identical conclusions for the same $\mathrm{Ss}$, but not with solutions of monosodium glutamate. A second group of 29 Ss demonstrated three hedonic distributions to increasing concentrations of sodium chloride and of sucrose-increased dislike, increased liking, or an increase followed by a distinct reduction.

Bimodal hedonic responses to increasing concentrations of sodium chloride were observed by Engen et al (1961) and Ekman \& Åkesson (1964) and, more recently, by our laboratory (Pangborn et al, 1970). Despite the fact that in the latter experiments the biphasic distribution occurred at all four solution temperatures tested $\left(0^{\circ} \mathrm{C}, 22^{\circ} \mathrm{C}, 37^{\circ} \mathrm{C}\right.$, and $\left.55^{\circ} \mathrm{C}\right)$, the question remains as to whether the response might be built into the S's task. For example, the judgment of degree of liking for artificial laboratory solutions could be based upon multiple frames of reference. For some, the sodium chloride may have improved the taste of the disliked distilled water blank, for others the salt may have decreased the palatability of the acceptable distilled water, while still other Ss could have neutral feelings (neither like nor dislike) about all the stimuli.

In the follow-up experiments reported herein, the same group of Ss were retested with another salt compound (monosodium glutamate) and with a paired-preference presentation of the previous concentrations of sodium chloride. Additionally, the same hedonic procedure used with the original group was tested on another set of Ss with both sucrose and sodium chloride.

\section{METHOD}

The first group of Ss consisted of five female and four male University employees with extensive previous experience in psychophysical testing of gustatory stimuli. Test sessions were held twice daily, 9:30-10:00 a.m. and 2:30-3:00 p.m., Monday through Friday. Test compounds consisted of sodium chloride and sucrose of reagent-grade purity and of an odorless monosodium glutamate (MSG) of the highest purity produced to order by Bioferm Division of International Minerals and Chemicals Corporation. Solutions were presented in randomized order at room temperature $\left(22^{\circ} \mathrm{C}\right)$ in $10-\mathrm{ml}$ portions in $50-\mathrm{ml}$ beakers. Samples were identified by two- and three-digit numbers on the aluminum lids. Distilled water was provided for oral rinsing; retasting of solutions was permitted, but swallowing was not allowed. All judging was done in individual partitioned booths, maintained at $22^{\circ} \mathrm{C}$. Ss were informed of the identity of the samples immediately after testing and provided with cake or cookies as "rewards." The number of replications per sample per method are indicated in the captions for the accompanying figures. Procedures for control and measurement of solution temperature for data presented in Fig. 1 have been reported previously (Pangborn et al, 1970).

Two test methods were compared with the same concentrations of sodium chloride among the first group of eight Ss: (1) single-sample presentation of eight salt stimuli with Ss rating hedonic value on a 9-point scale, where 1 = dislike extremely, $5=$ neither like nor dislike, and $9=$ like extremely; (2) paired presentation of all combinations of five concentrations of sodium chloride, with $\mathrm{Ss}$ being required to indicate which of the two they preferred. The same Ss also evaluated degree of liking for seven concentrations of MSG, selected

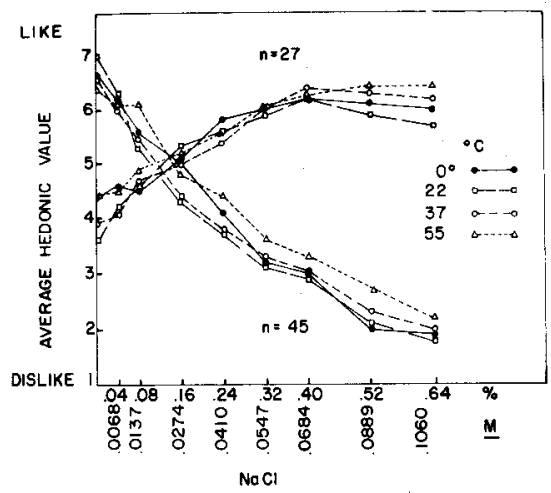

Fig. 1. Hedonic responses of eight Ss to distilled water and to increasing concentrations of sodium chloride at four solution temperatures. Individual points are the mean of the values indicated for the two groups (from Pangborn et al, 1970). during prescreening to be equivalent in saltiness intensity to the $\mathrm{NaCl}$.

The second group of Ss consisted of 29 male inmates at a nearby minimum security prison who were participating in a study on the influence of cigarette smoking on taste perception (Pangborn \& Trabue ${ }^{1}$ ). Using the aforementioned hedonic scale, Ss rated degree of liking for seven concentrations of sodium chloride and seven concentrations of sucrose.

\section{RESULTS AND DISCUSSION}

Figure 1 depicts the hedonic responses of eight Ss to sodium chloride at four solution temperatures, which were obtained in the original study (Pangborn et al, 1970). Three Ss indicated an increase in liking and five Ss indicated a decrease in liking with increasing salt levels at all of the temperatures, with no intermediate responses. Note that the responses to the distilled water control originated at different points for the two groups.

The responses of the same $S$ s to paired presentation of comparable salt concentrations are shown in Fig. 2. The lines designated as JG, TT, and RC are responses of the same three $\mathrm{Ss}$ who gave increasing hedonic responses in Fig. 1, whereas the remaining Ss in Fig. 2 are those whose hedonic responses show a decreasing trend with concentration in Fig. 1. (An additional S, D.C., was tested in the paired-preference test but was not available during the hedonic testing.) Only R.C. consistently preferred higher concentrations. Since the acceptance or rejection of the salt solutions was consistent within a $S$ between the two psychophysical methods, another salty substance, MSG, was tested among the same group, resulting in the data plotted in Fig. 3. Only R.C. showed some degree of liking for the concentrations presented, whereas the majority of the remaining

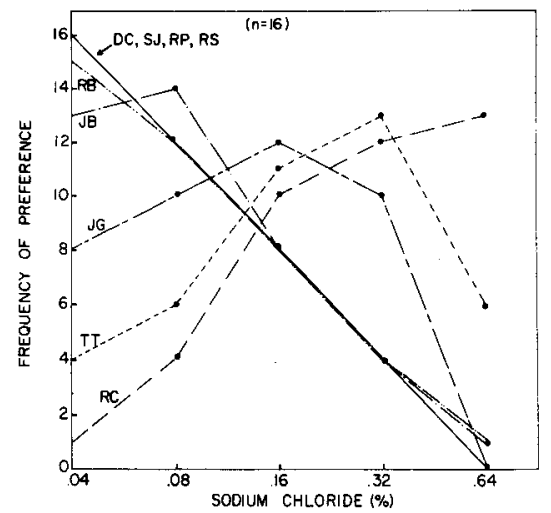

Fig. 2. Preferences for paired solutions of sodium chioride expressed by eight Ss. Each point is the mean of 16 separate judgments. 


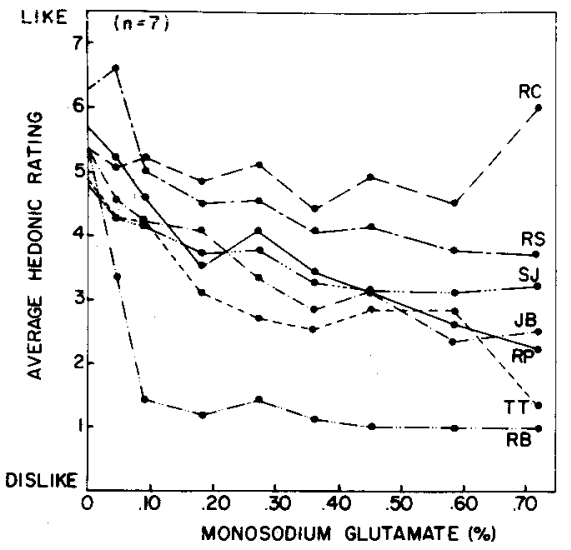

Fig. 3. Hedonic responses of seven Ss to distilled water and to increasing concentrations of monosodium glutamate. Individual points are the mean of seven separate judgments.

responses fell well below the neutral point of 5 on the scale. Analysis of variance of the ratings for MSG showed highly significant variability in response due to $S$ s, the nine concentrations, and the seven replicate sessions $(p<.001)$. This large variability may be attributable to the distracting, characteristic carryover taste of the MSG from one sample to the next, despite instructions to use distilled water for thorough oral rinsing between samples. It was evident throughout this test that MSG and $\mathrm{NaCl}$ elicit different kinds of salty sensations. Retesting with another salty compound was not possible, as no known substance except $\mathrm{NaCl}$ elicits a salty sensation only; other salts are either toxic (e.g., lithium chloride) or have multiple tastes, e.g., salty and bitter, or salty and metallic.

The second group of Ss demonstrated three types of distributions of hedonic responses to an even wider range of sodium chloride, as well as to sucrose (Fig. 4). The responses were not distributed randomly, as most Ss disliked the salt and liked the sugar solutions, as shown in Table 1 . The number of $S s$ in Table 1 include all 29 inmates who were tested, despite the fact that only 23 and 20 Ss, respectively, completed the entire series of replications

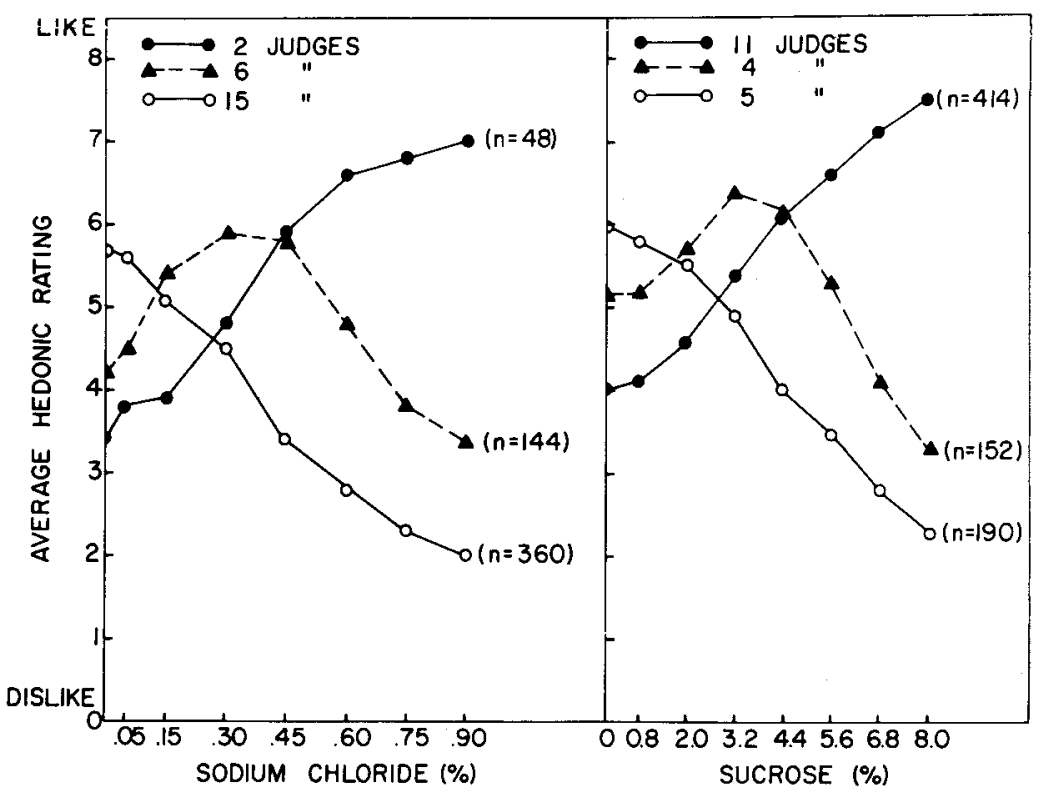

Fig. 4. Hedonic responses of 23 and $20 \mathrm{Ss}$, respectively, to increasing concentrations of sodium chloride and of sucrose, as well as to the distilled water blank. Each point is the mean of the number of individual judgments indicated in parenthesis.

for sodium chloride and sucrose plotted in Fig. 4. These data are in complete agreement with those reported for $18 \mathrm{Ss}$ by Engen et al (1961) but additionally show the emergence of a third distribution of increasing liking up to some maximum point, followed by a decrease. Most likely the Ss exhibiting the increasing degree of liking also would reach a maximum point if the concentrations were extended sufficiently. Again, the responses to the distilled water differed among the three groups so that they were starting from different baselines.

Several investigators have observed sucrose preferences and salt aversions among experimental animals, e.g., the results of Young \& Asdourian (1957) with need-free rats, that all concentrations of sucrose were hedonically positive and high concentrations of sodium chloride were hedonically negative. In his comprehensive text on motivation and emotion, Young (1961) details how affective processes depend upon knowledge, information,

Table 1

\begin{tabular}{lllrr}
\hline & \multicolumn{4}{c}{ Sodium Chloride } \\
\cline { 2 - 5 } & Dislike & Like & Like-Dislike $(\Lambda)$ & Totals \\
\hline Sucrose: & & & 1 & 6 \\
$\quad$ Dislike & 5 & 0 & 3 & 17 \\
$\quad$ Like & 12 & 2 & 3 & 6 \\
Like-Dislike $(\Lambda)$ & 3 & 0 & 7 & 29 \\
\hline Totals & 20 & 2 & & \\
\hline
\end{tabular}

training, and past experience. The individual S's past history would have to be explored to explain clearly the results reported herein. It would be of considerable interest to expand the experiment to include a large number of gustatory stimuli across a wide range of concentrations among a large population of Ss, varying the type of instruction given as well as the psychophysical methods.

\section{REFERENCES}

EKMAN, G., \& ÅKESSON, C. Saltiness, sweetness, and preference. A study of quantitative relations in individual subjects. Reports of the Psychology Laboratory, No. 177, University of Stockholm, 1964.

ENGEN, T., McBURNEY, D. H., \& PFAFFMANN, C. The sensory and motivating Pfaffmann in M. R. Jones (Ed.), Nebraska symposium on motivation, 1961. Lincoln: University of Nebraska Press, 1961. Pp. 71-110.

PANGBORN, R. M., CHRISP, R. B., \& BERTOLERO, L. L. Gustatory, salivary, and oral thermal responses to solutions of sodium chloride at four tempcratures. Perception \& Psychophysics, 1970, 8, 69-75.

YOUNG, P. T. Motivation and emotion. New York: Wiley, 1961.

YOUNG, P. T., \& ASDOURIAN, D. Relative acceptability of sodium chloride and sucrose solutions. Journal of Comparative \& Physiological Psychology, 1957, 50, 499-503.

\section{NOTE}

1. Pangborn, R. M., \& Trabue, I. M. Gustatory responses during periods of controlled cigarette smoking. Unpublished report, 1970. properties of the sense of taste. Cited by C. 